\title{
Lettuce (Lactuca Sativa) Growth Performance in Saltwater, Soil and Aquaponic System
}

\author{
Yap, Q.C \\ Teo, S.S. ${ }^{\rtimes}$
}

".2Department of Biotechnology, Faculty of Applied Sciences, UCSI University, Kuala Lumpur, Malaysia. 'Email:teoss@ucsiuniversity.edu.my Tel: 03-91018880

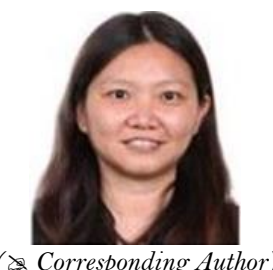

( Corresponding Author)

\begin{abstract}
Soil erosion is a major problem in most agricultural field where it threatened the whole ecosystem. Conventional planting included heavy applies of pesticides and fertilizer had given negative impact to the environment. Aquaponics of combining aquaculture and hydroponics in one integrated system is a useful revolutionary food production system. Salinity can inhibit the plant growth but saltwater aquaponics is studied as an extension from aquaponics recently. Lettuce is selected as the study plant species. A study had carried out by comparing the lettuce seeds germination and plants growth in soils and aquaponics, and lettuces growth with and without salt treatment in freshwater and saltwater aquaponics. The result showed no significance difference on seeds germination and plant growth between sandy soil and coconut coir soil $(\mathrm{P}>$ 0.05). Lettuces in aquaponics had the highest total water content, mean plant height increment, and most leaves. Germination of lettuce seeds that treated with different salt concentration was inhibited and the one treated with $0.2 \mathrm{M}$ salt solution had no germination. Growth of lettuces from saltwater were inhibited whether it was preliminary treated with salt or not whereas those from freshwater grew very well. In conclusion, aquaponics was more effective in growing lettuces than soils. Freshwater is more suitable to use for growing lettuces than saltwater. Saltwater inhibited lettuce growth whether with or without salt treatment. Waste product from aquaculture had successfully utilised as a nutrient source for growing crops.
\end{abstract}

Keywords: Lactuca sativa, Aquaponics, Saltwater, Soil.

Citation | Yap, Q.C.; Teo, S.S. (2019). Lettuce (Lactuca Sativa) Growth Performance in Saltwater, Soil and Aquaponic System. Agriculture and Food Sciences Research, 6(2): 203-210. History:

Received: 10 April 2019

Revised: 20 May 2019

Accepted: 2 July 2019

Published: 22 August 2019

Licensed: This work is licensed under a Creative Commons

Attribution 3.0 License (c) E E

Publisher: Asian Online Journal Publishing Group
Acknowledgement: Both authors contributed to the conception and design of the study.

Funding: This research was supported by Centre of Excellent for Research Value Innovation and Entrepreneurship (CERVIE) (Proj-In-FAS-026) and Faculty of Applied Sciences of UCSI University.

Competing Interests: The authors declare that they have no conflict of interests.

Transparency: The authors confirm that the manuscript is an honest, accurate, and transparent account of the study was reported; that no vital features of the study have been omitted; and that any discrepancies from the study as planned have been explained.

Ethical: This study follows all ethical practices during writing.

\section{Contents}

1. Introduction

2. Materials and methods. 


\section{Contribution of this paper to the literature}

This study contributes in the existing literature by comparing the lettuce seeds germination and plants growth in soils and aquaponics, and lettuces growth with and without salt treatment in freshwater and saltwater aquaponics.

\section{Introduction}

Lettuce, also known as Lactuca sativa, is a type of leafy vegetable from Asteraceae family, which produces crisp leaves loosely arranged on the stalk. It is easily cultivated and it grown as a hardy annual. Besides, it favors low temperature surroundings to prevent from flowering quickly. Moreover, the germination of lettuce seed usually takes around 2 to 8 days. Leaf lettuce will normally produce a crop within 50 to 70 days, while most heading varieties might require 60-80 days to mature [1]. Lettuce was considered to possess some medicinal qualities during medieval times in Europe [2]. Lettuce is riches in various vitamins and minerals, it also has several benefits such as anti-inflammatory properties, low cholesterol level, antioxidant properties, improve insomnia, antioxidant, antimicrobial, anti-cancer properties and control anxiety.

Traditional planting is the ancient food production system as it has been practiced for thousands of years. It is not only the oldest planting method in the world but also the main source of improving phase of planting technology such as conventional, modern and organic planting, that involved crops plantation using soils which required very large land space. Aquaponics is an integration of hydroponics and aquaculture, where crop plants and aquatic species can be grown together in a soilless water-based system [3, 4]. It is a soilless agricultural system that are highly productive, suitable for urban areas, and can address the shortage of land in relation to growing demand for food production. Aquaponics can be set-up in vertical integration systems in indoor urban settings, which address the limitations of soil quality and space availability [5]. It also helps cleanses the water through so called biofilter treatments. The nutrients that released from fish excreta and microbial breakdown of organic wastes had utilized by plants in aquaponic systems [6]. Salinity had also played an important role when it comes to crops plantation. Different level of salt concentration can affect the seed germination and growth of plants, especially to those plants that are weak in tolerating salts level [7]. Recently, the demand for seafood products on the global market is rising especially in Asian countries due to the increase in affluence and appreciation of the health benefits of seafood. Saltwater aquaponic system had been studied as an extension of aquaponics to grow seafood and high salt tolerance crops [8]. This study aimed to compare lettuce seeds germination and plants growth in soils and aquaponics, and lettuces growth with and without salt treatment in freshwater and saltwater aquaponics.

\section{Materials and methods}

\subsection{Lactuca Sativa (L. Sativa) Preparation and Germination}

The Lactuca sativa (L. sativa) seeds were soaked with $5 \% \mathrm{NaOCl}$ solution for 5 minutes to sterilize surface of the seeds. The seeds were washed with distilled water, drained and dried with tissue paper. LECA (Light Expanded Clay Aggregate), soil mixture (sandy soil, quartz, limestone, sandstone and shale) and coconut coir soil were used as medium for plant grow. L. sativa seeds were germinated in different media (soils, sandy soil and coconut coir soil) under different temperature $\left(15^{\circ} \mathrm{C}, 20^{\circ} \mathrm{C}, 25^{\circ} \mathrm{C}\right.$ and $\left.30^{\circ} \mathrm{C}\right)$ to screen for the $L$. sativa with the best growth performance and further compared with those in aquaponics. The plants were water twice a day. The $L$. sativa seedlings were transferred to a larger pot for growth observation after 10 days of germination.

\subsection{Aquaponic System}

\subsubsection{Lettuce Seeds with Salt Treatment in Saltwater}

Salinity experiment was to pre-treated lettuce seeds with different salt concentrations. Lettuce seeds were soaked with $0.025 \mathrm{M}, 0.05 \mathrm{M}, 0.1 \mathrm{M}$ and $0.2 \mathrm{M} \mathrm{NaCl}$ solution in petri dishes respectively. After the germination count for around 10 days, the lettuce seedlings were transferred to saltwater aquaponics system for growth observation.

\subsubsection{Lettuce Seeds without Salt Treatment in Freshwater and Saltwater}

Lettuce seeds were firstly germinated for 10 days. The lettuce seedlings were transferred to freshwater and saltwater aquaponic system for growth observation. The growth result of lettuces was used to compare with lettuces growth in sandy soil, coconut coir soil, and saltwater aquaponic system.

\subsection{Transfer Lettuce from Soil to Aquaponics}

After one month, the lettuces in soils that grow better were transferred from soils system to aquaponic system and allowed to continue grow for another 2 weeks.

\subsection{Data Collection}

The seed germination count was collected, final germination percentage, germination rate reduction of germination percentage, and seed viability index $[9,10]$ were calculated as followed:

Final germination percentage $=\frac{S}{T \times 100}$

$$
\text { Germination rate }=\frac{N 1}{D 1+\frac{N 2}{D 2+\cdots+\frac{N i}{D i}}}
$$

Where $\mathrm{S}$ is the number of germinated seeds, $\mathrm{T}$ is the total number of seeds and Ni number of germinated seeds, per day $(\mathrm{Di})$.

Reduction of germination percentage $=(1-$ The number of germinated seeds conditions salinity $/$ The number of germinated seeds conditions control $) \times 100$. 


\section{Seed viability index $=\frac{\text { Final germination percentage } \times \text { average seedling length }(\mathrm{mm})}{100}$}

Plant height, fresh weight, dry weight, leaf number, leaf color and weekly water quality analysis were measured and recorded.

\subsection{Statistical Analysis}

All the collected data were analysed with the means were compared using IBM SPSS Statistics 22.

\section{Results and Discussion}

\subsection{Lettuce Seeds Germination in Sandy Soil and Coconut Coir Soil}

Seeds germination in $15^{\circ} \mathrm{C}, 20^{\circ} \mathrm{C}$ and $25^{\circ} \mathrm{C}$ was not significantly different from $30^{\circ} \mathrm{C}$. Figure 1 showed that germination rate of lettuce seeds in sandy soil was slightly higher than that in coconut coir soil. From Figure 2 , final germination percentage had shown an adverse result whereby there is a higher germination percentage of lettuce seeds in coconut coir soil than sandy soil, with germination percentage of $90 \%-100 \%$, that is nearly all lettuce seeds had germinated. Consequently, sandy soil allowed a more rapid seed germination whereas coconut coir soil was able to provide a higher chance of success for more seeds to be germinated. Lettuce seeds grew the slowest at $15^{\circ} \mathrm{C}$ where the leaves opened very slowly while only shoot were elongated normally. On the other hand, the germination of lettuce seed in both soils was completely inhibited at $30^{\circ} \mathrm{C}$. At $15^{\circ} \mathrm{C}$, the germination and growth of seeds will be slowed down. Temperature of $30^{\circ} \mathrm{C}$ was very high for lettuces which leads to rapid dry out in soil although watering was applied. As a result, the sprouting process of seed was greatly inhibited due to overheating. The high temperature not only harmed the plant but also altered the taste of lettuce [11]. From the results, it showed that lettuces favoured growth under $25^{\circ} \mathrm{C}$. Moreover, high soil strength will impeded seedlings emergence and root growth, it also makes tilling more difficult and more energy demanding [12]. The loose structure in sandy soil provided large pore spaces which allow roots easy to move through the soil and shoots can emergence easily [13]. Hence, the seeds were able to germinate faster provided with favourable temperature. However, coconut coir soils contains lignin and cellulose that rich in potassium and various micronutrients such as $\mathrm{Fe}, \mathrm{Mn}, \mathrm{Zn}$, and $\mathrm{Cu}$, where it supplied more nutrients to seeds than sandy soil and allowed more seeds to germinate. The overall growth performance of seeds from sandy soil and coconut coir soil under $25^{\circ} \mathrm{C}$ was the best hence were chosen for comparison with those from freshwater aquaponics.

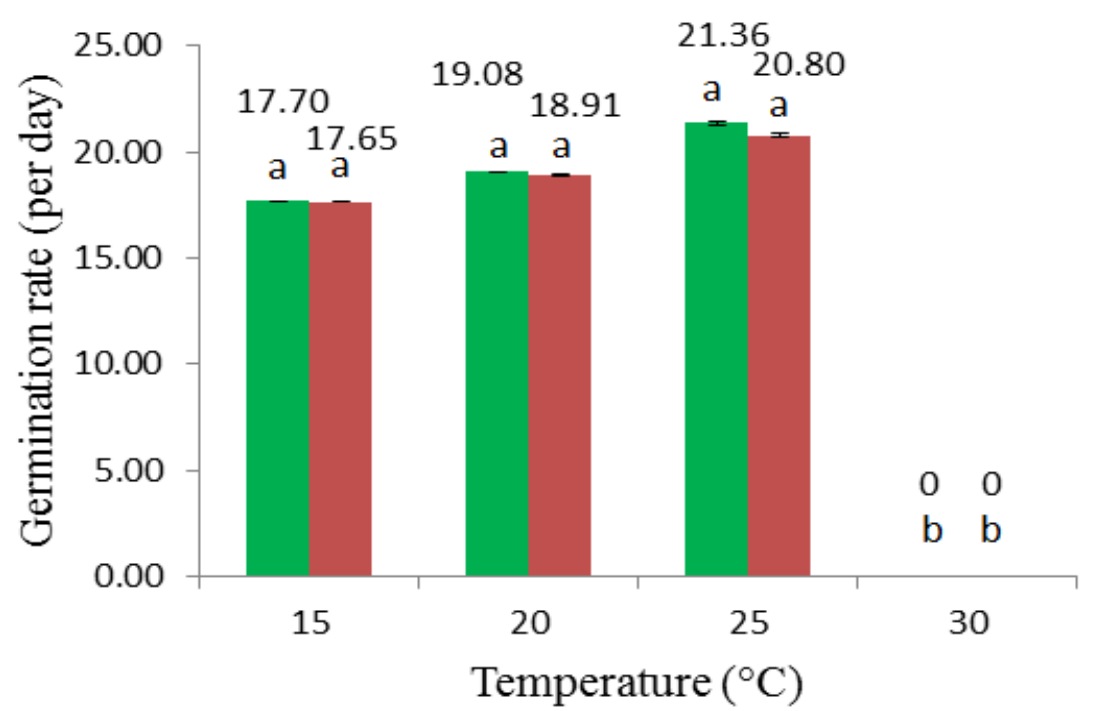

\section{- Sandy soil \\ - Coconut husk soil}

Figure-1. Germination rate of lettuce seeds with different temperatures $\left({ }^{\circ} \mathrm{C}\right)$ in sandy soil and coconut coir soil in 10 days. Means that are not followed by different letters were not significantly different at $\mathrm{P}<0.05$ level.

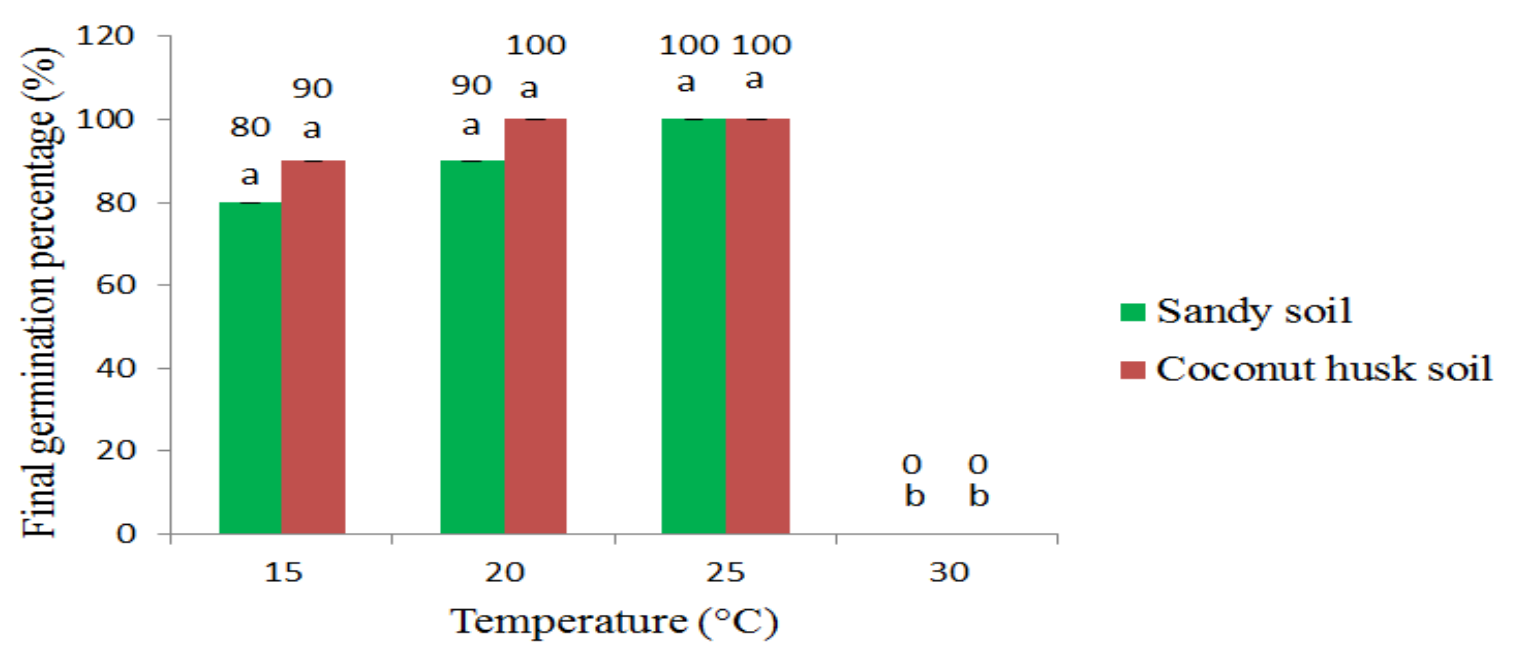

Figure-2. Final germination percentage (\%) of lettuce seeds with different temperatures $\left({ }^{\circ} \mathrm{C}\right)$ in sandy soil and coconut coir soil in 10 days. Means that are not followed by different letters were not significantly different at $\mathrm{P}<$ 0.05 level. 


\subsection{Lettuce Growth Rate in Sandy Soil, Coconut Coir Soil and Aquaponic System}

Overall, lettuce growth in sandy soil and coconut coir soil was significantly than that in aquaponics as shown in Figure 5. However, there is a drastic increase in mean height increment of lettuce in aquaponics than soils as shown in Figure 3. Aquaponics grew crops a lot faster than those in soil. In addition, there is significance difference between total water content of lettuces that grew in coconut coir soil, sandy soil and aquaponic system. Lettuces from aquaponics had highest total water content, whereas the total water content in sandy soil was lower than that in coconut coir soil Figure 4. Based on Table 1, lettuces from aquaponics was largest in size and had the most average number of leaves. Lettuces in soils grew a lot slower than lettuces from aquaponics as the plant was very small, the leaves were still tiny even grew for a month. Growth of lettuces in sandy soil was the poorest among all, the leaves started to turn yellow while lettuces in other systems remained as fresh green colour. Lettuces from coconut coir soil was slightly better had chosen and transferred to aquaponics for 2 weeks, the mean plant height of lettuce had increased, with $41.0 \mathrm{~mm}$ difference and total water content of $174.9 \mathrm{mg}$ had indicated improvement. Table 2 showed the average number of leaves also increased, faster than in soil. Physical structure of soil is the important properties where it greatly influenced all physical processes that take place such as thermal conductivity, water holding capacity, permeability, and aeration [12]. Soil structure can affect water supply to plants and influences nutrients availability. Coconut coir fibre possessed better water and nutrient retention ability therefore it produced crops with higher water content. Sandy soil has very weak water retention ability, low organic matter content, and poor soil fertility. Large particle properties made sandy soil does not hold much water hence applied water will be drained away [14]. In addition, it had low nutrient holding capacity, lead to rapid leaching of native or added nutrient [15]. Therefore, sandy soil produced less healthy lettuces. Although coconut coir soil riches in many nutrients, however it has low Cation Exchange Capacity (21-30 meq./L) where it does not retain cations or buffer against $\mathrm{pH}$ well [16]. Even coco coir has the capacity to hold nutrients, but it can also "lock" them up at the same time which leaded to nutrient deficiencies. Aquaponics supported the growth of lettuces more efficiently hence the plants were able to grow very fast in short time interval. The water content indicated can potentially be achieved by the plant. Hence, aquaponics is built in a closed, recirculating system [17] itself utilized the water and nutrient source directly from fish tank which provided sufficient nutrients to lettuces and no drying issue will occur.

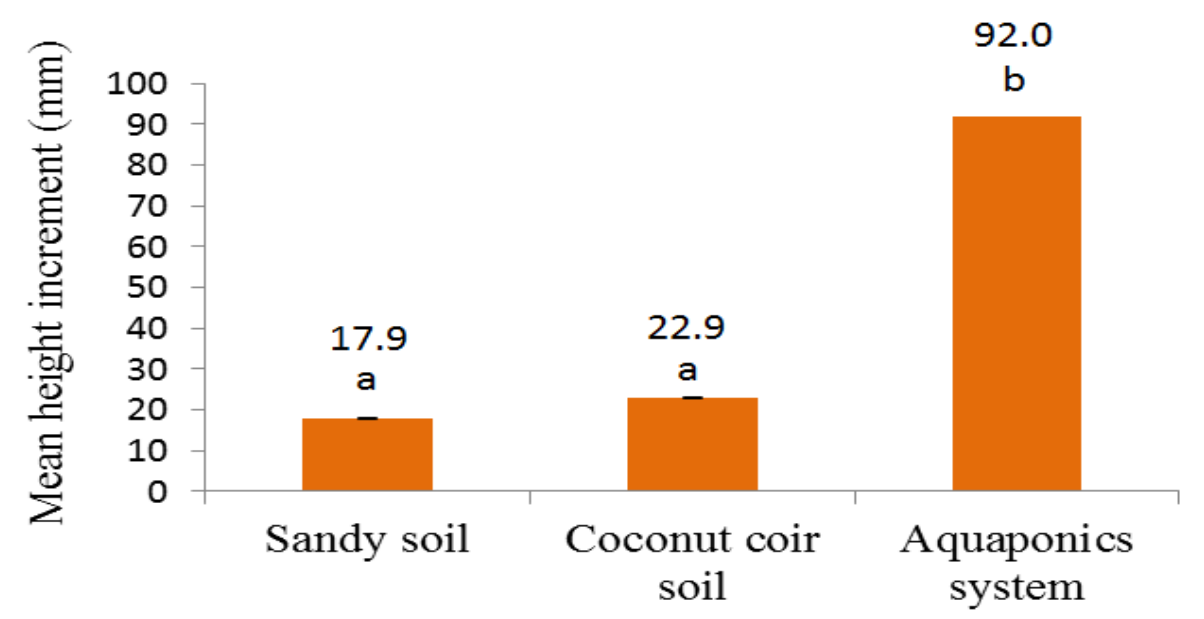

Planting systems

Figure-3. Mean height increment of lettuces in sandy soil, coconut coir soil and aquaponic system after a month. Means that are not followed by different letters were not significantly different at $\mathrm{P}<0.05$ level.

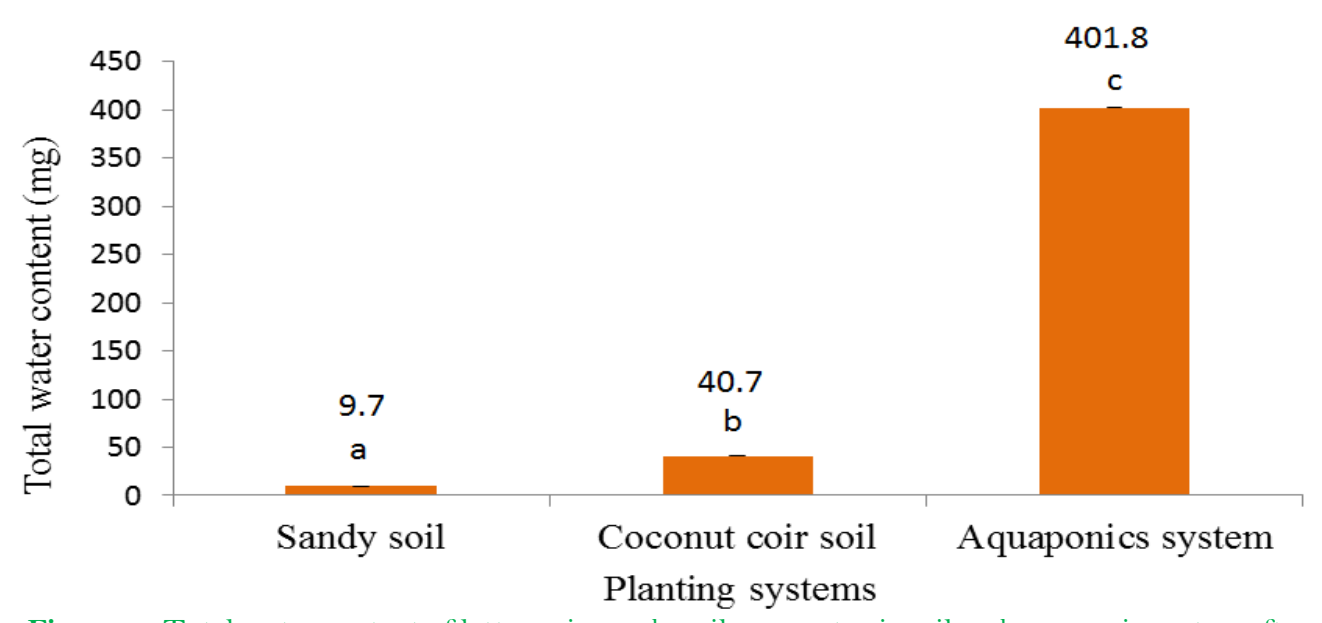

Figure-4. Total water content of lettuces in sandy soil, coconut coir soil and aquaponic system after a month. Means that are not followed by different letters were not significantly different at $\mathrm{P}<0.05$ level. 


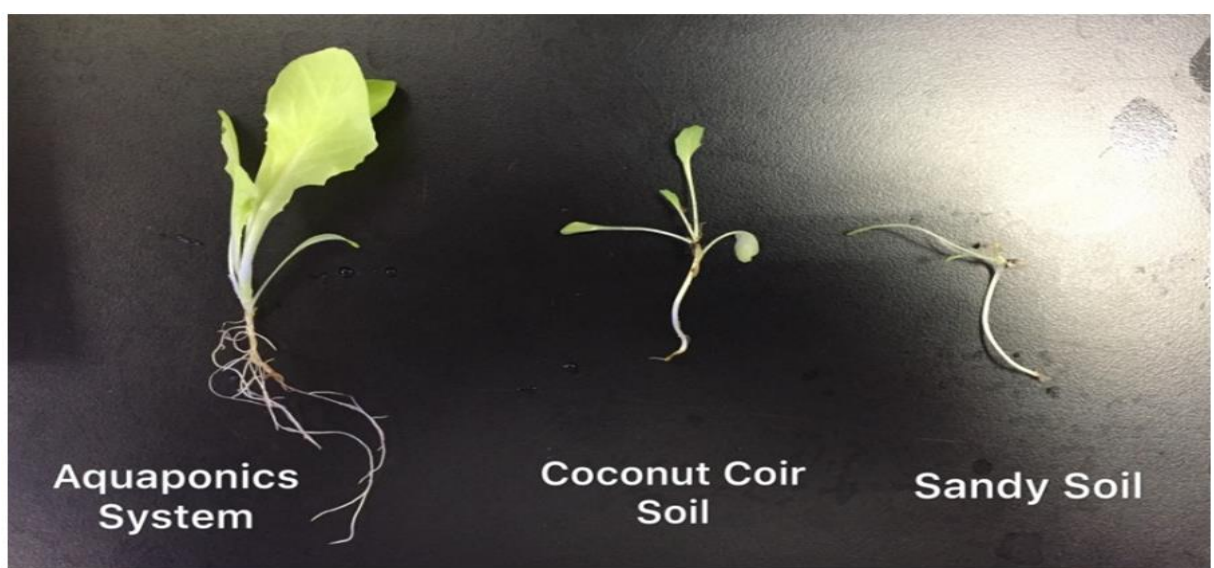

Figure-5. Growth of lettuces in sandy soil (right), coconut coir soil (middle) and aquaponic system (left) after a month.

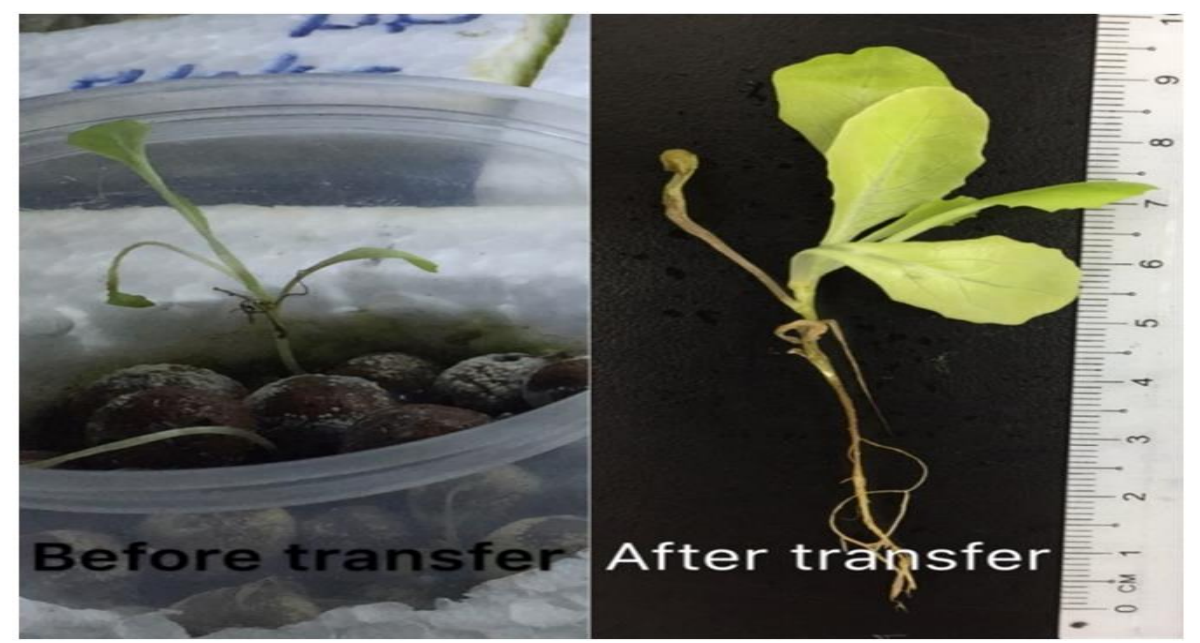

Figure-6. Growth of lettuces before and after transferred from coconut coir to aquaponic

system for 2 weeks.

Table-1. Average leaf number and leaf colour of lettuces in aquaponics system,coconut coir soil, and sandy soil after a month.

\begin{tabular}{c|c|c|c}
\hline \multirow{2}{*}{ Parameters } & \multicolumn{3}{|c}{ Planting System } \\
\cline { 2 - 4 } & Aquaponics & Coconut coir soil & Sandy soil \\
\hline Average leaf number & 7 & 4 & 3 \\
\hline Leaf colour & Fresh green & Fresh green & Yellow \\
\hline
\end{tabular}

Table-2. Mean plant height, total water content, average leaf number and leaf colour in lettuces before and after transferred from coconut coir soil to aquaponic system for 2 weeks.

\begin{tabular}{c|c|c}
\hline \multirow{2}{*}{ Parameters } & \multicolumn{2}{|c}{ Planting System } \\
\cline { 2 - 3 } & Before transfer & After transfer \\
\hline Mean plant height $(\mathrm{mm})$ & 58.0 & 99.0 \\
\hline Total water content $(\mathrm{mg})$ & 22.9 & 174.9 \\
\hline Average leaf number & 4 & 7 \\
\hline Leaf colour & Fresh green & Fresh green \\
\hline
\end{tabular}

3.3. Salt Stress on Lettuce Seeds Germination

Germination of lettuce seeds treated with different salt concentrations were inhibited, both the germination rate and final germination percentage were lower than that of the control. Seed germination of lettuce seeds that treated in $0.025 \mathrm{M}, 0.05 \mathrm{M}$ and $0.1 \mathrm{M}$ salt solutions was not significantly different Figure 8 and germination percentage were all reduced to $85 \%$ Figure 9. Although the seeds were affected by salt stress but the level of affection was considered not too severe. There is no germination in lettuce seeds treated with $0.2 \mathrm{M}$ salt. From the result, it was indicated that lettuce seeds able to tolerate salt stress below 0.2M salt concentration. Reduction of germination percentage in lettuce seeds from different salt concentrations level also showed greatest reduction in 0.2M Figure 10. Furthermore, salt stress also resulted in loss of seed viability index. As expected, seeds treated with $0.2 \mathrm{M}$ salt solution loss seed viability index the most Figure 11. Growth of lettuce seeds with salt treatment was mostly slightly shorter in length than control. Indeed, high salt level will inhibit the germination of new seeds. Seeds were still able to grow when salinity is not too high but slower than the seeds with tap water only, due to the salinity that acted as drought on plants which prevents roots from performing their usual osmotic activity. Moreover, water and nutrients will travel from an area of low concentration into an area of high concentration. Water and nutrients unable to migrate into plant roots, preventing water uptake by germinating seeds [7]. As salinity levels increased, stress on germinating seedlings will also increase. 


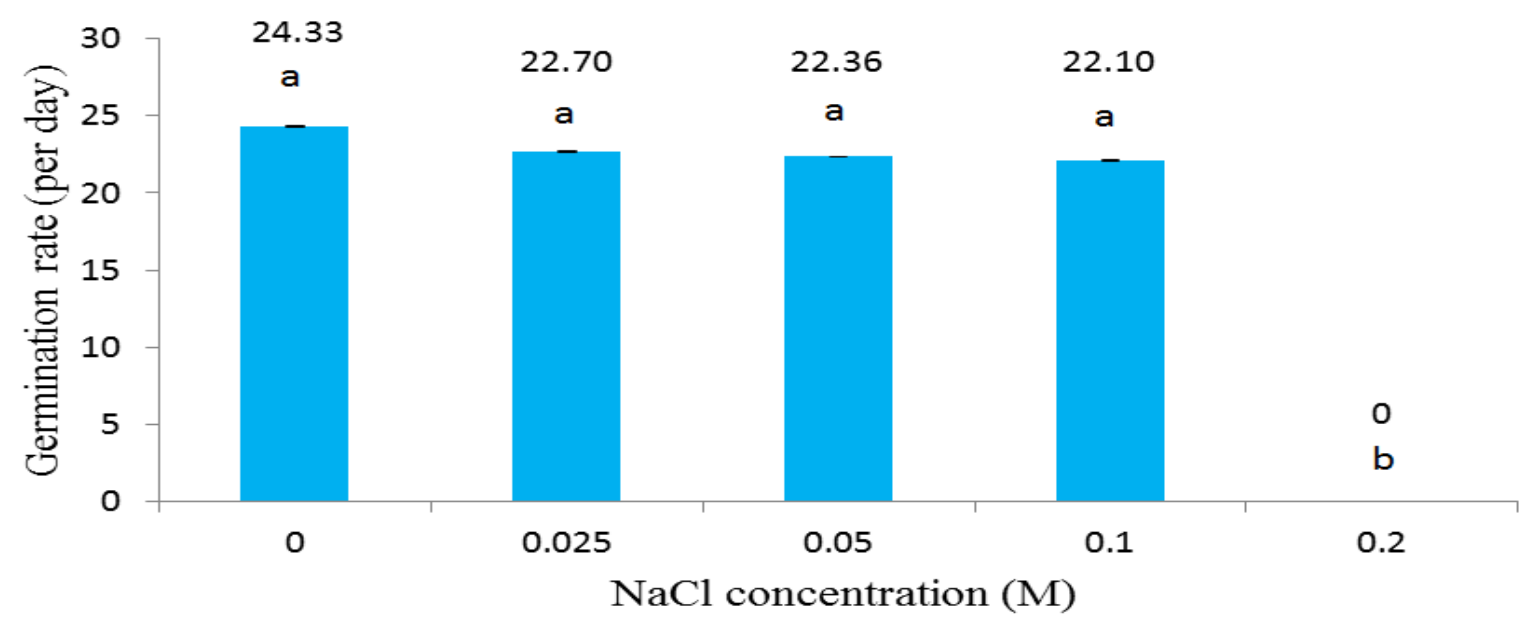

Figure-7. Germination rate of lettuce seeds in different $\mathrm{NaCl}$ concentrations (M) in 10 days. Means that are not followed by different letters were not significantly different at $\mathrm{P}<0.05$ level.

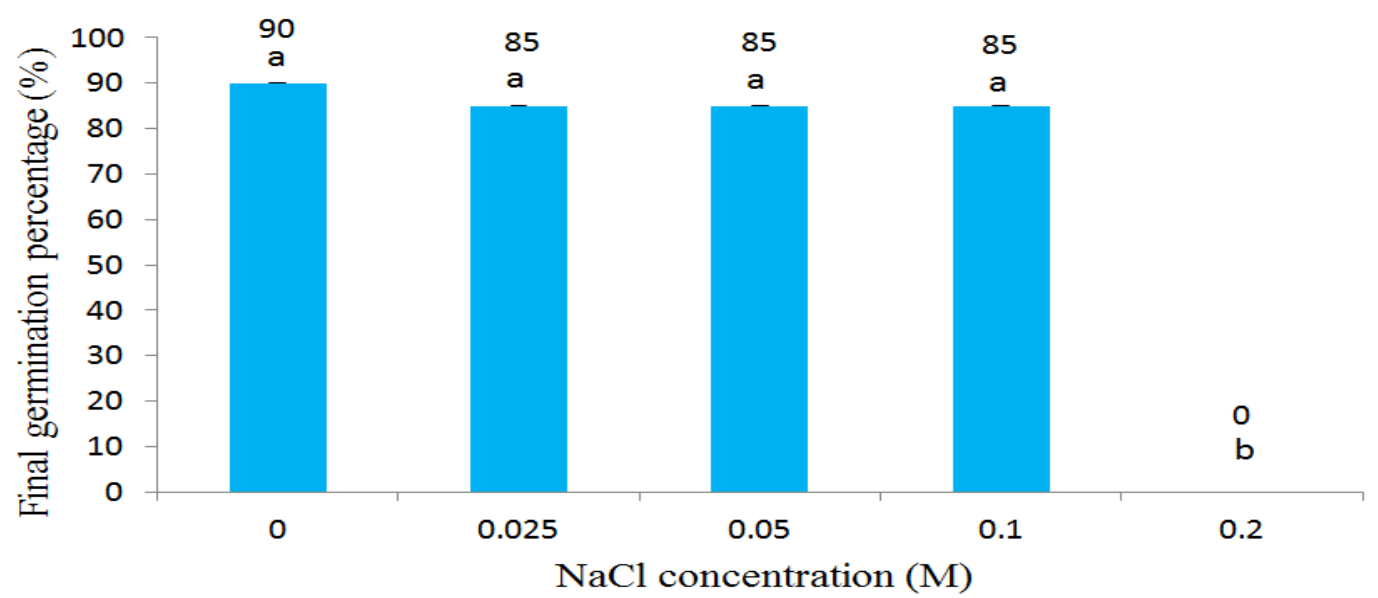

Figure-8. Final germination percentage (\%) of lettuce seeds in different $\mathrm{NaCl}$ concentrations (M) in 10 days. Means that are not followed by different letters were not significantly different at $\mathrm{P}<0.05$ level.

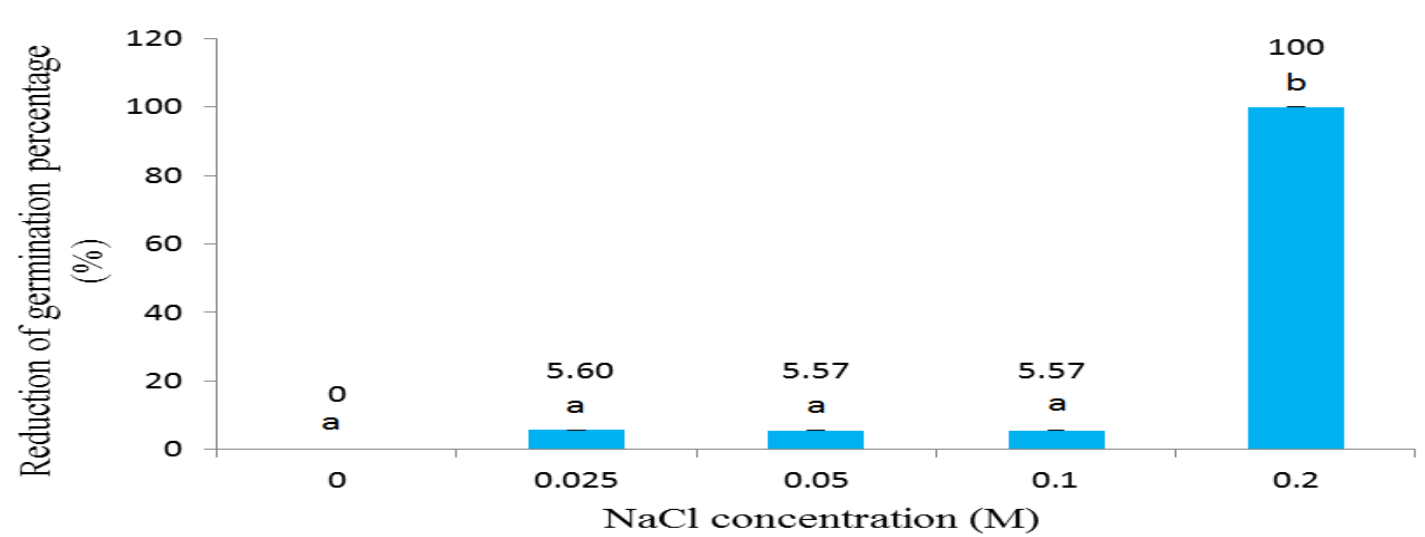

Figure-9. Reduction of germination percentage (\%) of lettuce seeds in different $\mathrm{NaCl}$ concentrations (M) in 10 days. Means that are not followed by different letters were not significantly different at $\mathrm{P}<0.05$ level.

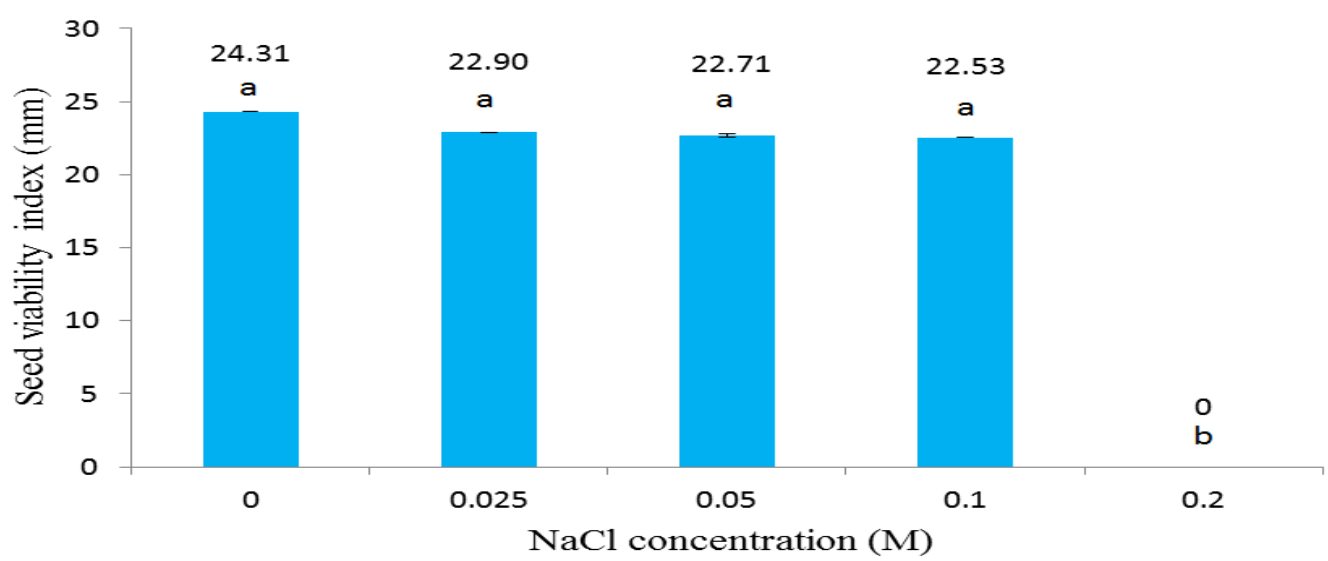

Figure-10. Seed viability index (mm) of lettuce seeds in different $\mathrm{NaCl}$ concentrations (M) in 10 days. Means that are not followed by different letters were not significantly different at $\mathrm{P}<0.05$ level.

\subsection{Lettuce Growth Rate in Freshwater and Saltwater Aquaponics System}

From Figure 11, there was no significance difference of lettuces growth in saltwater whether lettuces were treated with salt or no salt treatment as there were no changes in mean height increment after a month. Total water content in lettuces with and without salt treatment was $3.7 \mathrm{mg}$ and $3.3 \mathrm{mg}$ respectively, which was lower than control as shown in Figure 12. Lettuce from freshwater showed normal growth while there was no growth in lettuce from saltwater. Lettuces from saltwater were thin and tiny, no change of height and no sign of growing new leaf, however no significance difference in leaf colour with control Table 3. Texture of lettuce without salt treatment was soft and mushy while the lettuce with salt treatment was slightly rigid. Based on weekly water 
quality analysis in Table 4 and Figure 13, since saltwater aquaponics is of seawater, $\mathrm{Na}^{+}$concentration is very high $(8267 \mathrm{ppm})$ that greatly reduced lettuce growth. High $\mathrm{Na}^{+}$concentration indicated increase starvation of essential nutrients from plants, it may also increase the chance for root diseases to occur. High $\mathrm{K}^{+}$concentration in saltwater had induced deficiencies of nutrients such as nitrogen, calcium and magnesium [18]. Saltwater also has high $\mathrm{Ca}^{2+}$ concentration that had caused lock up of various nutrients such as potassium, magnesium, manganese and iron. Excess $\mathrm{Ca}^{2+}$ ion in water tank came in contact with sulphur, it will precipitated and remained at bottom of the tank. It also decreases the uptake of cation nutrients such as phosphorus, boron, copper and zinc [19]. On the other hand, the conductivity in saltwater was too high and had prevent efficient water absorption in the root zone by plant. However, low levels of phosphate in saltwater had limited plant and algae growth [20]. The soft and mushy texture in plants indicated loss of turgidity as they were no longer can maintain themselves in shape, ultimately culminating in cell death [21]. Besides, whether the plants were preliminary treated with salt or no salt solution had no effect on growth since both of them were inhibited. Salinity tolerance level in lettuce was not capable of growing in saltwater aquaponics, it is still preferred to grow in freshwater aquaponic system.

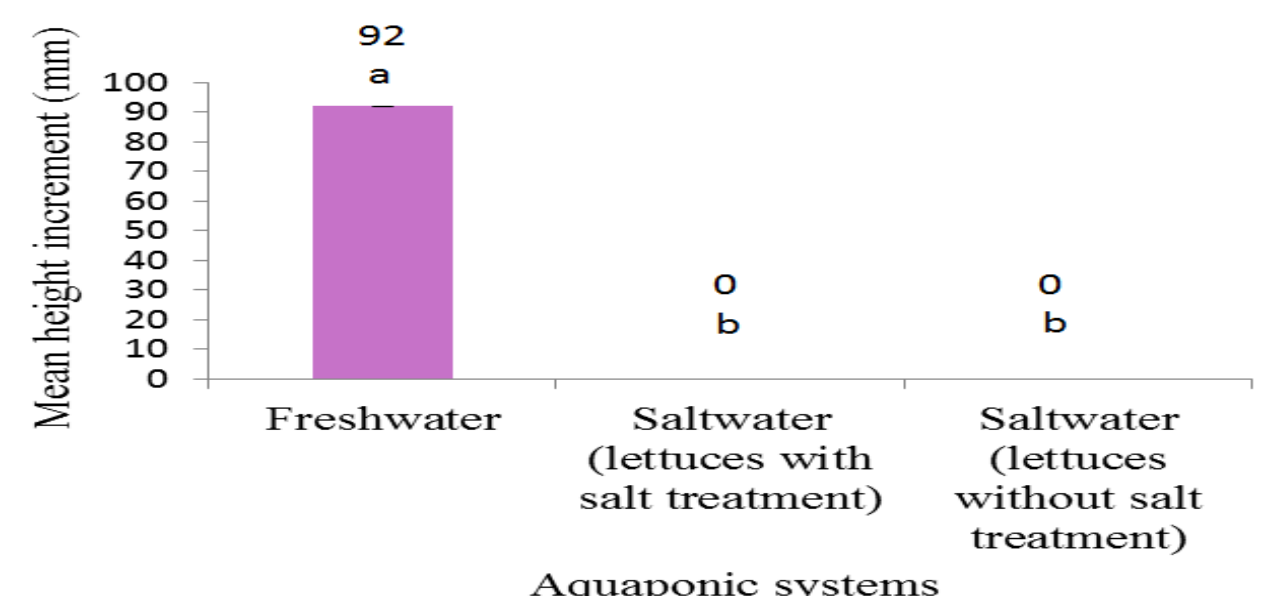

Figure-11. Mean height increment of lettuces in freshwater aquaponic system (control), and saltwater aquaponic system (lettuces with salt treatment and without salt treatment) after a month. Means that are not followed by different letters were not significantly different at $\mathrm{P}<0.05$ level.

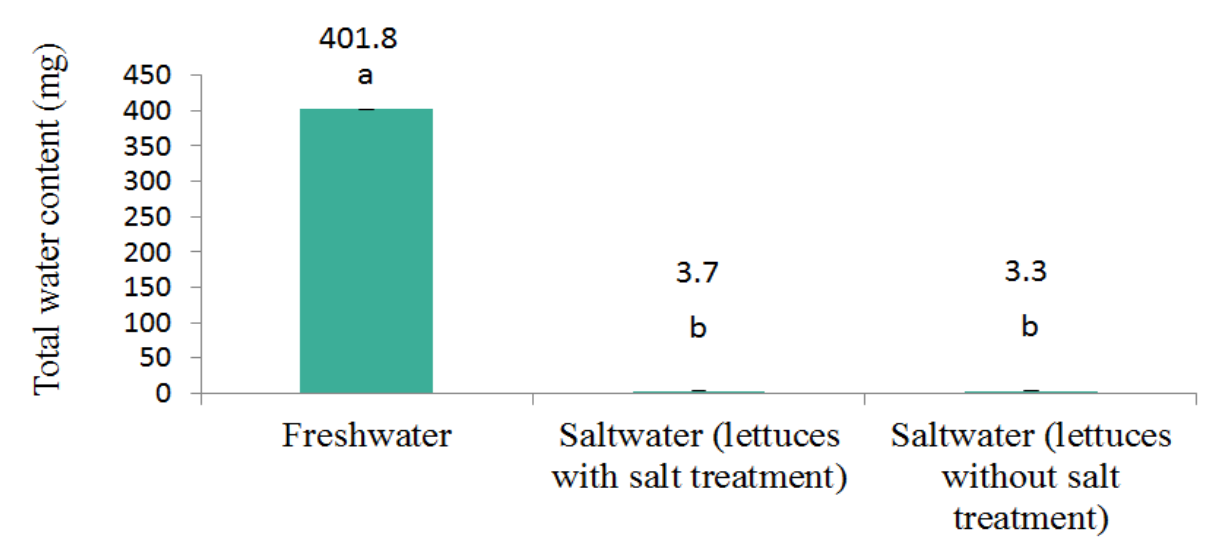

Aquaponic systems

Figure-12. Total water content of lettuces in freshwater aquaponic system (control), and saltwater aquaponic system (lettuces with salt treatment and without salt treatment) after a month. Means that are not followed by different letters were not significantly different at $\mathrm{P}<0.05$ level.

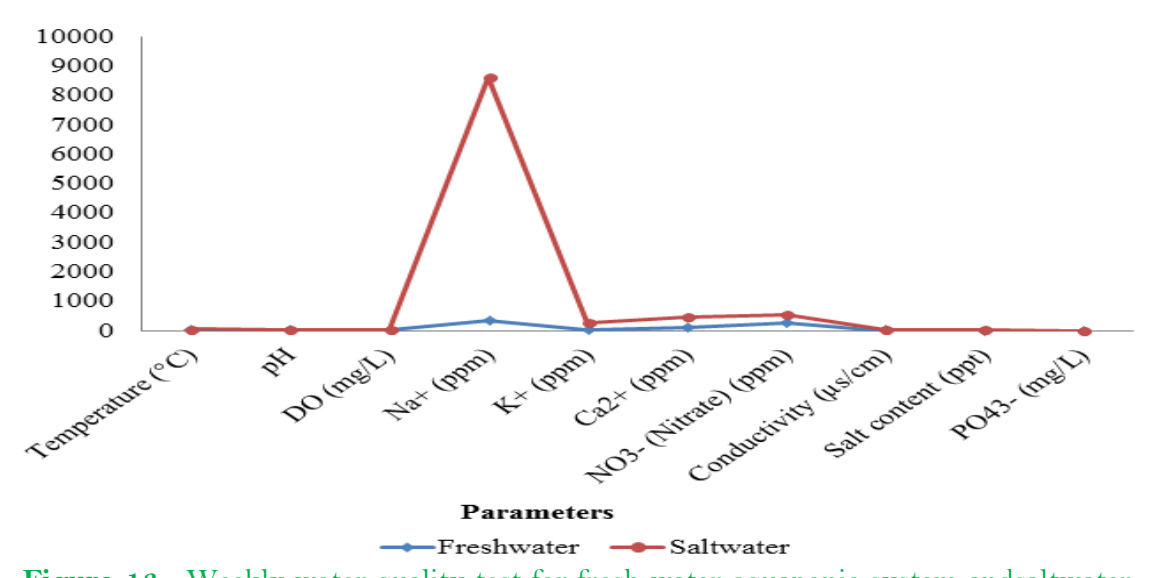

Figure-13. Weekly water quality test for fresh water aquaponic system andsaltwater aquaponic system.

Table-3. Average leaf number and leaf colour of lettuces in freshwater aquaponic system and saltwater aquaponic system (lettuces with salt treatment and without salt treatment) after a month.

\begin{tabular}{c|c|c|c}
\hline \multirow{2}{*}{ Parameters } & \multicolumn{3}{|c}{ Aquaponics system } \\
\cline { 2 - 4 } & Control & With salt treatment & Without salt treatment \\
\hline Average leaf number & 7 & 2 & 2 \\
\hline Leaf colour & Fresh green & Fresh green & Fresh green \\
\hline
\end{tabular}


Table-4. Weekly water quality test for freshwater aquaponic system and saltwater aquaponic system.

\begin{tabular}{|c|c|c|}
\hline \multirow[b]{2}{*}{ Parameters } & \multicolumn{2}{|c|}{ Aquaponics System } \\
\hline & Freshwater & Saltwater \\
\hline Temperature $\left({ }^{\circ} \mathrm{C}\right)$ & $22.1 \mathrm{a}$ & $22.3 \mathrm{a}$ \\
\hline $\mathrm{pH}$ & $7.53 \mathrm{a}$ & $7.65 \mathrm{a}$ \\
\hline $\mathrm{DO}(\mathrm{mg} / \mathrm{L})$ & $6.12 \mathrm{a}$ & $6.86 \mathrm{a}$ \\
\hline $\mathrm{Na}^{+}(\mathrm{ppm})$ & $340 a$ & $8267 \mathrm{~b}$ \\
\hline $\mathrm{K}^{+}(\mathrm{ppm})$ & $24 a$ & $233 \mathrm{~b}$ \\
\hline $\mathrm{Ca}^{2+}(\mathrm{ppm})$ & $123 a$ & $333 \mathrm{~b}$ \\
\hline $\mathrm{NO}^{3-}$ (Nitrate) (ppm) & $272 \mathrm{a}$ & $273 \mathrm{a}$ \\
\hline Conductivity $(\mu \mathrm{s} / \mathrm{cm})$ & $3.2 \mathrm{a}$ & $33.5 \mathrm{~b}$ \\
\hline Salt content (ppt) & $1.5 \mathrm{a}$ & $19.8 \mathrm{~b}$ \\
\hline $\mathrm{PO}_{4}{ }^{3-}(\mathrm{mg} / \mathrm{L})$ & $2.0 \mathrm{a}$ & $0.5 \mathrm{~b}$ \\
\hline
\end{tabular}

Note: Means that are not followed by different letters were not significantly different at $\mathrm{P}<0.05$ level.

\section{Conclusion}

In a nutshell, people started to use soil-less based planting method to grow lettuces as they would want to save more space and increase crop yield. From the study, sandy soil and coconut coir soil had exerted insignificant effect $(\mathrm{P}>0.05)$ on lettuce growth. It involved the mixing of different composition of soils in order to improve the crop growth, where it was complex and time wasting. Contrary to the previous method, a simple setting of aquaponic system was easily to be monitored and controlled. The result shown was also obviously more effective where it grew healthier lettuces in shorter time interval than the soil does. Lettuce was moderate salt tolerance plant where it can only withstand water salinity up to around $0.2 \mathrm{M}$. Therefore, freshwater aquaponics was more suitable in growing them rather than saltwater aquaponics due to extreme high salt level that lead to osmotic inhibitory in plants. Saltwater aquaponics will inhibited the growth of lettuces whether with or without preliminary salt treatment. More research is required in the future to develop this aquaponic system with valuable cash crops that could thrive in sea water. Aquaponic system had successfully aquacultured the waste materials. Waste product from fishes had to be eliminated from the system as it contains high amount of ammonia which will cause toxic effect that will lead to illness to the fishes. However, the nitrifying bacteria had turned this toxic material into nitrate that act as a food source for plants to grow. Future research may investigate the lettuce yield with different system design of aquaponics, specific patterns of nutrient availability and uptake, cost-benefit analysis of lettuce productivity, and different aspects of lettuces and other crops under aquaponics or other soilless systems.

\section{References}

[1] S. Y. Zee and L. H. Hui, Hong Kong food plants. United States: Urban Council, 1990.

[2] C. P. Khare, Indian herbal remedies: Rational western therapy, ayurvedic, and other traditional usage, Botany. Germany: Springer Science \& Business Media, 2004.

[3] D. E. Seawright, R. R. Stickney, and R. B. Walker, "Nutrient dynamics in integrated aquaculture-hydroponics systems," Aquaculture, vol. 160, pp. 215-237, 1998. Available at: https://doi.org/10.1016/s0044-8486(97)00168-3.

[4] J. E. Rakocy, T. M. Losordo, and M. P. Masser, "Recirculating aquaculture tank production systems: Integrating fish and plant culture, Southern region," Aquacul Center Publication, vol. 454, pp. 1-16, 2006.

[5] F. Orsini, R. Kahane, R. Nono-Womdim, and G. Gianquinto, "Urban agriculture in the developing world: A review," Agronomy for Sustainable Development, vol. 33, pp. 695-720, 2013.

[6] H. R. Roosta and M. Hamidpour, "Effects of foliar application of some macro-and micro-nutrients on tomato plants in aquaponic and hydroponic systems," Scientia Horticulturae, vol. 129, pp. 396-402, 2011

[7] M. M. Azooz and P. Ahmad, Plant-environment interaction: Responses and approaches to mitigate stress. United States: John Wiley \& Sons, 2016.

[8] V. Nozzi, G. Parisi, D. D. Crescenzo, M. Giordana, and O. Carnevali, "Evaluation of dicentrarchus labrax ,eats and the vegetable quality of beta vulgaris var. cicla farmed in freshwater and saltwater aquaponic systems," Water, vol. 8, pp. 1-14, 2016.

[9] M. Azizi, M. Chehrazi, and S. M. Zahedi, "Effects of salinity stress on germination and early growth of sweet William (Dianthus barbatus)," Asian Journal of Agricultural Sciences, vol. 3, pp. 453-458, 2011.

[10] M. J. Seghatoleslami, "Effect of salinity on germination of Satureja hortensis L., Cichorium intybus L. and Cynara scolymus L," Iranian Journal of Agricultural Research, vol. 8, pp. 818-823, 2010.

[11] L. Shepherd, The complete guide to growing vegetables, flowers, fruits, and herbs from containers: Everything you need to know explained simply. United States: Atlantic Publishing Company, 2011.

[12] R. Lal, Encyclopedia of soil science. United States: CRC Press, 2006.

[13] Victorian Department of Agriculture, The Journal of Agriculture vol. 73:. United States: Victorian Department of Agriculture 1975 K. T. Osman, Soils: Principles, properties and management. Germany: Springer Science \& Business Media, 2012.

R. S. Jackson, Wine science: Principles and applications, 4th ed. Netherlands: Elsevier, 2014.

K. A. Handreck, "Properties of coirdust, and its use in theformulation of soillesspotting media," Communications Soil E Plant Anal, vol. 24, pp. 349-363, 1993.

[17] R. V. Tyson, D. D. Treadwell, and E. H. Simonne, "Opportunities and challenges to sustainability in aquaponic systems," Hort Technology, vol. 21, pp. 6-13, 2011. Available at: https://doi.org/10.21273/horttech.21.1.6.

[18] R. D. Merrill, A. A. Shamim, A. B. Labrique, H. Ali, K. Schulze, M. Rashid, P. Christian, and K. P. West Jr, "Validation of two portable instruments to measure iron concentration in groundwater in rural Bangladesh," Journal of Health, Population, and Nutrition, vol. 27, pp. 414-418, 2009. Available at: https://doi.org/10.3329/jhpn.v27i3.3384.

[19] S. Arora, A. K. Singh, and Y. P. Singh, Bioremediation of salt affected soils: An Indian perspective. Germany: Springer, 2017.

[20] D. Willis, L. May, Y. Gutema, and N. Whittlesey, Measuring economic benefits of water pollution abatement in an irriated river basin. United States: DIANE Publishing, 1992.

[21] B. L. Querijero and A. L. Mercurio, "Water quality in aquaculture and non-aquaculture sites in Taal Lake, Batangas, Philippines," Journal of Experimental Biology and Agricultural Sciences, vol. 4, pp. 109-115, 2016 